\title{
Development of polyamide 6 based single polymer composites reinforced by novel stitched plain fabrics
}

\author{
Shafagh D. Tohidi ${ }^{\mathrm{a}, \mathrm{b}, \mathrm{c}, *}$, Zlatan Denchev ${ }^{\mathrm{a}}$, Nadya V. Dencheva ${ }^{\mathrm{a}}$, Ana Maria Rocha ${ }^{\mathrm{c}}$, Livia A. Rosa ${ }^{\mathrm{c}}$, \\ Bernhard Engesser ${ }^{\mathrm{d}}$
}

${ }^{a}$ IPC - Institute for Polymers and Composites, Department of Polymer Engineering, University of Minho, Guimarães, Portugal

${ }^{\mathrm{b}}$ CMEMS - Center for Micro-Electro Mechanical Systems, University of Minho, Guimarães, Portugal

${ }^{\mathrm{c}}$ Center of Textile Science and Technology (2C2T), Department of Textile Engineering, University of Minho, Guimarães, Portugal

d Jakob Müller AG, Frick, Switzerland

\section{A R T I C L E I N F O}

\section{Keywords:}

Single polymer composite

Polyamide 6

Microcapsules

Woven reinforcements

Image processing

Compression molding

\begin{abstract}
A B S T R A C T
In the present study, novel woven reinforced single polymer composites (WSPC) based on polyamide 6 (PA6) is developed via a combination of powder-coating of PA6 textile reinforcements with PA6 empty microcapsules (EMC) and compression molding techniques. Activated anionic ring-opening polymerization of $\varepsilon$-caprolactam was employed to synthesize the PA6-EMC which was transformed during the compression molding into WSPC matrix without damaging the PA6 textile reinforcements. A promising novel class of PA6 woven fabrics, stitched plain, which are patented by Jakob Müller company $\mathrm{AG}^{\circledR}$ were used as reinforcements. The tensile properties of stitched plain reinforced WSPC were studied and compared to ones reinforced by the plain-woven structure and the PA6 neat matrix reference materials. The parametric studies are performed on the stress field along the elements of reinforcements, using image processing to correlate the influence of reinforcement architectures with the failure mechanism of WSPC.
\end{abstract}

\section{Introduction}

Single polymer composites (SPC) are novel promising composite materials in which reinforcements are made of the same polymer as the matrix [1]. H-bonds or even covalent bonding across the interface are possible in SPC thus enhancing the adhesion at the matrix/reinforcements interface resulting in full transfer of the load from the matrix to the reinforcement [2]. The key benefit of SPC is their full recyclability by reprocessing [3]. There are usual techniques for SPC preparation comprising powder impregnation, hot compaction, overheating of fibers (partially melting), film-stacking, co-extrusion [4-8]. All these techniques are considered as partial melting of the reinforcing material due to the creation of matrix component and consolidate the final composite part. Since in SPC both, the matrix and the reinforcement elements originate from the same polymer material, the most important factor that influences the mechanical performance of the composite is the preservation of the reinforcement's structure and morphology during processing.

Up to date, most of the attention has been merely paid to the optimization of the polymerization process and production techniques of PA6-based SPC in order to increase the processing window [9-14].
Gong and Yong [15] prepared all-polyamide based woven reinforced SPC using film stacking technique and studied their static and dynamic tensile properties. The processing temperature was reported by $33{ }^{\circ} \mathrm{C}$ and the tensile strength of the SPC showed $280 \%$ improvement as compared to the neat PA6 matrix component (69 MPa). They continued their study on preparation of aliphatic PA6 based SPC reinforced by PA6 based plain woven structure via in situ anionic ring opening polymerization (AAROP) of $\varepsilon$-caprolactam [10]. Their result depicted the optimum processing temperature up to $80{ }^{\circ} \mathrm{C}$ as well as $108 \%$ higher tensile strength (154 MPa) as compared to the pure PA6 polymer at $160{ }^{\circ} \mathrm{C}$ optimum molding temperature. Oliveira et al. [13] studied the multiscale thermoplastic laminate composites based on PA6 dually reinforced by carbon fiber woven textile structures and different micronsized metal particles using microencapsulation strategy. Two main steps appropriated comprising producing shell-core PA6 microcapsules loaded with 13-19\% metal activated via AAROP of ECL in the presence of different metal particles. In the second step, the loaded PAMC were distributed between textile plies with fiber volume fractions $V_{f}=25 \%$ or $V_{f}=50 \%$. Their results showed 4 times growth of the tensile stiffness and stress at break while compared with the PA6 neat material.

The influence of the reinforcement architecture, fiber volume

\footnotetext{
* Corresponding author at: Center of Textile Science and Technology (2C2T), Department of Textile Engineering, University of Minho, Guimarães, Portugal.

E-mail address: Shafagh.project@gmail.com (S.D. Tohidi).
} 

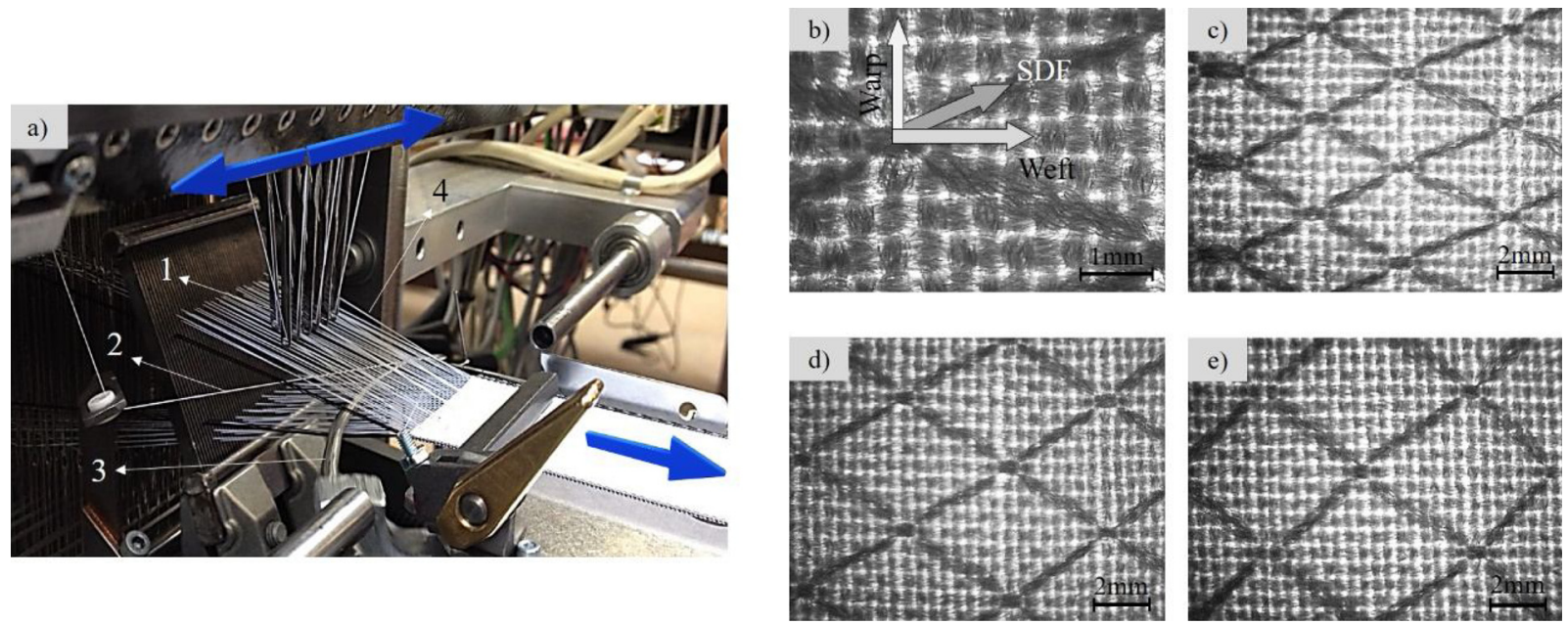

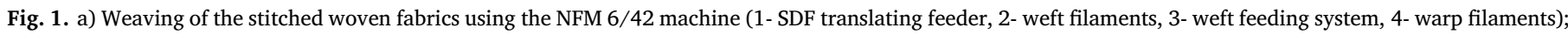

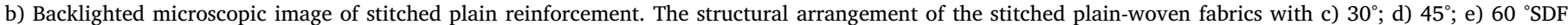
gradients.

fraction and ply orientation on the mechanical properties of textilereinforced composite materials has attracted the attention of various researchers previously [16-21]. Lomov et al. [19] characterized the tensile damage of tri-axial braid quasi-unidirectional woven/epoxy composites. The tensile tests, accompanied with acoustic emission (AE) registration and full-field strain measurement on the surface of composite samples was carried out to identify characteristic strain levels at the first $\left(\varepsilon_{1}\right)$, well-developed $\left(\varepsilon_{2}\right)$ and just before the final $\left(\varepsilon_{3}\right)$ fracture of the samples. Their results showed that the damage initiation occurred by transverse cracks (inter-filament and intra-filament failure), delamination at the boundaries of the fiber bundles and onset of filament failure during the ultimate breaking of the sample. Gao et al. [20] studied the damage development of laminates of satin woven, epoxysized carbon-fiber-reinforced polyimide with $60 \%$ fiber content. They concluded that the transverse matrix cracking and delamination in the crimp regions was the major problem in fracturing of these composites. Todo et al. [21] studied the effect of various strain rates, ranging from $10^{-2}$ to $10^{1} \mathrm{~s}^{-1}$, on the tensile properties of four different plain woven/ polyamide composites. Two types of reinforcements, carbon fiber (CF) and glass fiber (GF), and two matrices, polyamide-6 (PA6) and modified polyamide- 6 (mPA6) were used. Their results demonstrated that the better tensile performance at all testing rates was achieved for CF-mPA6 composites. By polarized light microscopy studies, an extensive microcracking was detected in the matrix at the transverse filaments' region, prior to their mechanical failure. The internal micro- and mesogeometry of the reinforcement was considered the main factor of the damage mechanism in textile reinforced composites.

To the best of our knowledge, the geometrical/structural effect of woven reinforcement on mechanical behavior of PA6 based SPC has not yet characterized. Moreover, the relationship between the internal and external stress fields in SPC during mechanical straining have not been dealt with in depth. Meanwhile, the present study aims at the development and stress field analysis of PA6-based single polymer composites reinforced by stitched plain-woven structures that the latter being very recently developed by Jakob Müller $\mathrm{AG}^{\circledR}$ Company. To produce these WSPC, the reinforcing textile structures were annealed under stretch and then powder-coated with EMC that were previously synthesized via AAROP of ECL in solution. The final composite was obtained by the consolidation of the powder-coated textile plies by compression molding. The effect of woven reinforcement geometry, its fiber volume fraction and ply orientation on the overall tensile properties of these WSPC was investigated. The results demonstrated an improvement of $63 \%$ of tensile stiffness in case of stitched plain reinforced WSPC when compared to the PA6 neat matrix reference. Furthermore, applying stitched diagonal filaments on plain substrate caused modification of elastic modulus of stitched plain reinforced WSPC about ca, $12 \%$ as compared with those reinforced with plain structures. The better matrix/reinforcement interfacial bonding in case stitched plain reinforced WSPC is explained by performing image processing techniques on tensile surface fracture of the composites. All these techniques are applied to justify the effect of reinforcement's architecture on the tensile properties of the newly developed WSPC.

\section{Material and experimental test method}

\subsection{Reagents}

All the solvents used in this study were of the puriss grade purchased from Sigma-Aldrich (USA) that were used as-received. The $\varepsilon$ caprolactam (ECL) monomer was delivered by Brüggemann Chemical, (Germany) and kept under vacuum for $1 \mathrm{~h}$ at $23^{\circ} \mathrm{C}$ before any AAROP. The activator, Brüggolen C20 P (C20) was purchased from the same supplier and used without further treatment. According to the manufacturer's data, C20 contains $80 \mathrm{wt} \%$ of blocked diisocyanate in ECL. The initiator sodium dicaprolactamato-bis-(2-methoxyethoxo)-aluminate (DL) was delivered from Katchem (Czech Republic) and used as received.

\subsection{Woven reinforcements}

The novel stitched reinforcements are plain weave structures diagonally stitched (SDF) with air jet textured PA6 filaments (160 dtex) and produced on a NFM 6/42 loom. The samples were delivered by the Jakob Müller company AG ${ }^{\circledast}$, Switzerland (Fig. 1a). As it can be seen in Fig.1a, the stitching yarn feeding system (translating feeder) is driven by separate stepper motors to diagonally stitch the filaments on the warp and weft filaments. Thus, altering the stitching points changes the gradient of the stitched diagonal filaments (SDF) over the base substrate (Fig. 1b). In this study, three SDF gradients, namely, $30^{\circ}, 45^{\circ}$ and $60^{\circ}$ over a plain weave substrate were considered (Fig. 1c-d).

\subsection{Pre-treatment of the woven textile plies}

All woven reinforcement plies were pre-washed with the same type of non-ionic detergent solution at $30{ }^{\circ} \mathrm{C}$ for $30 \mathrm{~min}$ to diminish contaminations and then rinsed with reverse osmosis water for another 15 min. To eliminate any non-chemically bonded hydrophobic finish oligomers from the surface, all samples were immersed in acetone for 30 

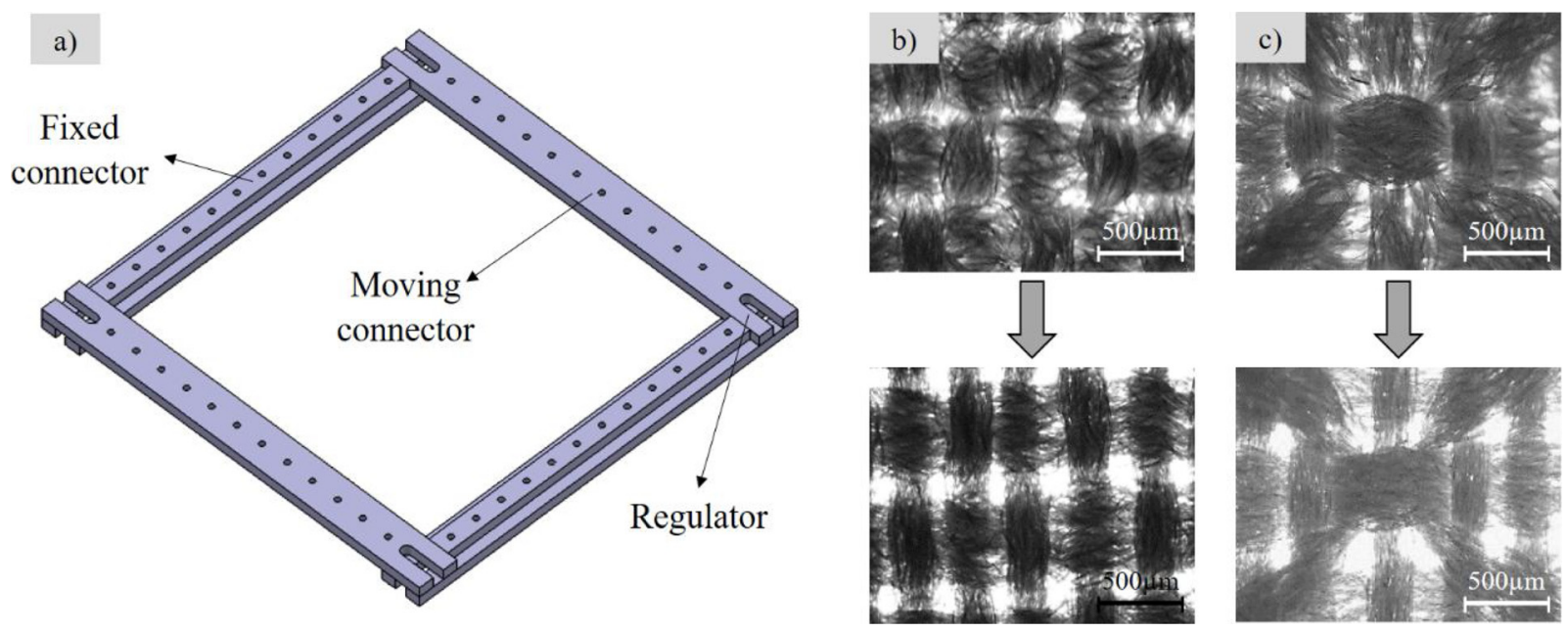

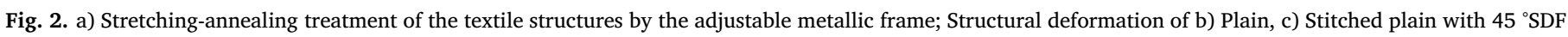
gradient (as a representative sample) before (top images) and after annealing (bottom images).

min and then dried for $120 \mathrm{~min}$ at $60{ }^{\circ} \mathrm{C}$. To induce the necessary mechanical properties and geometrical stability, all woven structures were biaxially stretched to $30 \%$ of their original length using a specially designed metal frame and a screen stretching apparatus (Fig. 2a). The stretched reinforcement textiles were then annealed at $170{ }^{\circ} \mathrm{C}$ for 90 min with fixed ends. As seen in Fig. 2b-c, this stretching-annealing procedure caused a clear deformation of the woven reinforcements.

Table 1 shows the warp and weft density, areal weight and thickness of the woven reinforcement samples, before and after the stretch-annealing treatment.

\subsection{Preparation of WSPC}

In a preliminary stage, solution-precipitation AAROP of ECL to PA6 empty microcapsules (EMC) was performed. The polymerization procedure has been previously described in detail [22,23]. In summary, 2 mol of ECL monomer was dissolved in boiling 1:1 v/v toluene/xylene mixture under nitrogen atmosphere and then the initiator DL and activator C20 were introduced. After $60 \mathrm{~min}$ at $125-135{ }^{\circ} \mathrm{C}$ under constant stirring the anionic PA6 was produced in the form suspension in the hydrocarbon mixed solvent. The EMC were separated from the reaction mixture by vacuum filtration followed by washing with methanol and drying.

The WSPC with different reinforcement architectures, fiber content and ply orientation were prepared by a combination of two techniques: powder-coating of PA6 woven reinforcements with EMC followed by compression molding. This combination was denominated as powder coating-compression molding (PCCM) technique. The consolidation of the ply sets by compression molding was performed in a hydraulic hot press (Moore, UK) using a mold with dimensions $70 \times 70 \times 2 \mathrm{~mm}$. Three fiber volume fractions $\left(V_{f}, \%\right)$ i.e., 15,20 and $25 \%$ were applied to produce the WSPC samples. The $V_{f}, \%$ determined according to the following equation.

$V_{f}, \%=\frac{\mathrm{A}_{\mathrm{w}} \cdot \mathrm{N}}{\rho_{\mathrm{f}} \cdot \mathrm{t}} \times 100$

where $A_{w},\left(\mathrm{~g} / \mathrm{m}^{2}\right)$ is the areal weight of the textile reinforcement, $N$ is the number of plies, $\rho_{f},\left(\mathrm{~g} / \mathrm{m}^{3}\right)$ is the density of the PA6 filaments and $t$ $(\mathrm{m})$ is the laminate thickness [24].

The limit range of $V_{f}=25 \%$ was considered because above it the embedded woven textiles at the upper and lower WSPC surfaces were visibly damaged after the compression molding. The mold conditions were set at $5 \mathrm{MPa}$ pressure and $215{ }^{\circ} \mathrm{C}$ temperature for $10 \mathrm{~min}$. The selected mold temperature led to an acceptable processing window of ca. $10{ }^{\circ} \mathrm{C}$, which was the difference between the melting point of the PA6 woven reinforcements and above that of the matrix-forming PA6 empty microcapsules. At the end of compression molding, all composites were cooled down to $50{ }^{\circ} \mathrm{C}$ at a rate of ca. $40{ }^{\circ} \mathrm{C} / \mathrm{min}$. Table 2 presents all sample specifications and designation. The selection of 15 and $25 \%$ fiber content for warp and weft wise annealed stitched plain (SP-A) reinforced WSPC respectively was based on the better tensile properties of $15 \%$ and $25 \% V_{f}$ P-A reinforced composites in corresponding directions which was considered by preliminary tensile tests.

\subsection{Morphological characterization}

The polarized light microscopic (PLM) studies of embedded filaments were carried out using an Olympus $\mathrm{BH}-2$ light microscope (Japan), equipped with Leica Application Suite 4 software. To measure the cross-sectional dimensions of the embedded reinforcements, OpenCV library (written in Python programming language) was employed. Moreover, a NanoSEM-200 apparatus of FEI Nova (USA), using mixed secondary electron/back-scattered electron in-lens detection was used to assess the reinforcement/matrix bonding state at the surface

Table 1

Sample designation and properties of woven reinforcements.

\begin{tabular}{|c|c|c|c|c|c|c|c|}
\hline Reinforcement & Treatment & SDF gradient & Sample Designation & Warp density (filaments/cm) & Weft density (filaments/cm) & Areal weight $\left(\mathrm{g} / \mathrm{m}^{2}\right)$ & Thickness (mm) \\
\hline \multirow[t]{2}{*}{ Plain } & $x$ & - & $\mathrm{P}$ & 22 & 16 & $147.6 \pm 1.7$ & $0.58 \pm 0.01$ \\
\hline & $\checkmark$ & - & P-A & 20 & 12 & $111.0 \pm 2.1$ & $0.42 \pm 0.01$ \\
\hline \multirow[t]{6}{*}{ Stitched Plain } & $x$ & 30 & SP30 & 22 & 14 & $138.4 \pm 0.9$ & $0.61 \pm 0.01$ \\
\hline & $x$ & 45 & SP45 & 22 & 14 & $128.1 \pm 1.1$ & $0.55 \pm 0.01$ \\
\hline & $x$ & 60 & SP60 & 22 & 14 & $131.3 \pm 2.0$ & $0.55 \pm 0.01$ \\
\hline & $\checkmark$ & 30 & SP30-A & 19 & 12 & $111.8 \pm 2.0$ & $0.41 \pm 0.01$ \\
\hline & $\checkmark$ & 45 & SP45-A & 19 & 12 & $108.7 \pm 1.6$ & $0.37 \pm 0.01$ \\
\hline & $\checkmark$ & 60 & SP60-A & 19 & 12 & $110.4 \pm 2.1$ & $0.38 \pm 0.01$ \\
\hline
\end{tabular}


Table 2

The designation of laminate WSPC composites.

\begin{tabular}{|c|c|c|c|c|}
\hline Samples & Designation & $\begin{array}{l}\text { Woven reinforcement } \\
\text { architecture }\end{array}$ & $V_{f}, \%$ & $\begin{array}{l}\text { Plies } \\
\text { Number }\end{array}$ \\
\hline $\begin{array}{l}\text { Neat PA6 } \\
\text { matrix }\end{array}$ & PN & - & - & - \\
\hline \multirow[t]{6}{*}{ WSPC } & PU-P $\left(0\right.$ or $\left.90^{\mathrm{a}}\right)-15$ & Annealed Plain & 15 & 3 \\
\hline & PU-P(0 or $\left.90^{\mathrm{a}}\right)-20$ & reinforcement & 20 & 4 \\
\hline & PU-P $\left(0\right.$ or $\left.90^{\mathrm{a}}\right)-25$ & & 25 & 5 \\
\hline & PU-SP-SDF angle & Annealed Stitched & 15 & 3 \\
\hline & ${ }^{b}-\left(0\right.$ or $\left.90^{a}\right)-15$ & Plain reinforcement & & \\
\hline & $\begin{array}{l}\text { PU-SP-SDF angle } \\
{ }^{b}-\left(0 \text { or } 90^{\text {a }}\right)-25\end{array}$ & & 25 & 5 \\
\hline
\end{tabular}

${ }^{\text {a }}$ Unidirectional laminating of woven textile reinforcements in which 0 and 90 stand for warp and weft directions respectively.

b The SDF angle ( $\left.{ }^{\circ}\right)$ in stitched plain reinforcements are displayed by $30^{\circ}, 45^{\circ}$, and $60^{\circ}$.

fracture of the WSPC. Au/Pd alloy was applied to sputter-coat the samples to be observed.

Image processing techniques were carried out using the MATLAB ${ }^{\circledR}$ algorithm to analyze the fractured surfaces of WSPC after tensile breakage and then to link to the final tensile behavior of the composites. Image segmentation and biaxial image profile techniques were employed for further in-depth image analysis.

\subsection{Mechanical characterization}

Five woven reinforcement test specimens with $150 \times 100 \mathrm{~mm}$ dimension were tensile tested according to ASTM D5034 (grab test) standard, using an Instron 4505 machine equipped with a load cell of $2.5 \mathrm{kN}$ and at a constant crosshead speed of $2 \mathrm{~mm} / \mathrm{min}$. The neat textile samples were stored after stretching-annealing for $5 \mathrm{~h}$ in a controlled environment at $23^{\circ} \mathrm{C}$.

The tensile test of WSPC was performed according to ASTM D638, in an Instron 4505 testing machine at $23 \pm 2{ }^{\circ} \mathrm{C}$ with a standard load cell of $50 \mathrm{kN}$, gauge length of $38 \mathrm{~mm}$ and at a constant crosshead speed of 2 $\mathrm{mm} / \mathrm{min}$. All samples were stored for 30 days at $23{ }^{\circ} \mathrm{C}$ and $65 \%$ relative humidity before testing. Normalized test specimens were cut by laser from one and the same composite plate. At least five specimens of each sample were studied to calculate the average values and their standard deviation.

\section{Results and discussion}

\subsection{Tensile properties of woven reinforcements}

The typical tensile stress-strain behavior of plain and Stitched plain (SFD gradient of $60^{\circ}$ ) reinforcements (as a representative sample) with and without stretching-annealing treatment, is depicted in Fig. 3a. For the untreated woven reinforcements, the initial zone presents a low slope due to the decrimping and crimp-interchange (up to $10 \%$ tensile strain) of the filaments within the structure. Afterward, the stress-strain curve gradient increases steeply reaching its peak, which can be attributed to the filaments elongation and is governed by the level of filaments crimp and distortion (Fig. 3b). The elastic stiffness of all reinforcements is measured in reasonable strain range between $3-4 \% \varepsilon$. This selection is compatible with the elastic region of WSPC that is discussed in section 3.2. The stretching-annealing treatment released strain residuals by converting amorphous portions of the filaments to crystal [25]. Therefore, the tensile rigidity and strength of woven reinforcements were significantly modified after treatment (Fig. 3b).

The tensile properties of all stretched-annealed woven reinforcements in two principal directions in the warp $\left(0^{\circ}\right)$ and weft $\left(90^{\circ}\right)$ directions are shown in Table 3. The Young's modulus (E) was calculated from the stress-strain curves as the tangent at $3-4 \% \varepsilon$ (see Fig. 3b). The different warp and weft densities in woven reinforcements caused their significant anisotropic properties. The elastic modulus of the stitched plain significantly strengthened, up to $360 \%$ and $20 \%$ in the warp and weft directions, respectively when compared to the plain fabrics references in the corresponding directions. Increasing the gradient of SDF decreased the tensile stiffness of SP-A structures. The SP30-A sample demonstrated the highest tensile stiffness in the warp (101 MPa) and weft $(7 \mathrm{MPa}$ ) directions among the SP-A reinforcements which were measured by $35 \%$ and $218 \%$ higher than SP45-A samples (as a sample with lowest tensile properties) in corresponding directions. The highest tensile strength of c.a. 22-23 MPa was obtained with the SP60-A sample in the weft and warp directions, demonstrating an improvement factor of $18-20 \%$ when compared to the P-A structures.

\subsection{Tensile properties of WSPC}

Fig. 4 shows representative stress-strain curves in the tension of P-A and SP-A reinforced WSPC together with the ones of the PN matrix presented as a reference sample. These graphs demonstrate a nonlinear elastic behavior followed by a pseudo-plastic before reaching ultimate stress demonstrated at the early stages of tensile loading. The nonlinearity of PA6 based-WSPC assumed by shear deformation of the longitudinal filaments, extensional deformation of the matrix component and transverse cracking of the filaments is known as micromechanical deformations [26].

In general, P-A reinforced WSPC demonstrated superior tensile properties than the PN reference (Fig. 4). In the warp tested samples $\left(0^{\circ}\right)$ a more ductile behavior was observed due to their higher strain at break. On the contrary, the stress-strain behavior of WSPC in the weft direction (Fig. 4) registered an abrupt drop in stress magnitude, which represents a brittle failure mode. Embedding stitched plain reinforcements remarkably improved the tensile stiffness and strength of the reference samples. The WSPC reinforced by SP-A reinforcements also showed strain hardening caused by higher strain at break (Fig. 4). It is interesting to note that, the SP-A reinforced WSPC demonstrated necking in the plastic zone, detected by the gradual decrease in the stress-strain curve after the ultimate strength.

The most important tensile properties of all WSPC are tabulated in Table 4. Their tensile properties are correlated with reinforcement orientation (warp- $0^{\circ}$ and weft- $90^{\circ}$ ), fabric architectures (plain and stitched plain) and fiber volume fractions (15, 20 and $25 V_{f}$,\%). Increasing the fiber volume fraction from 15 to $25 V_{f} \%$ was caused a reduction on tensile properties of warp wise plain reinforced WSPC although it was on a contrary trend in case of the composites reinforced in the weft direction. As it can be seen in Table 4, applying SP-A reinforcements significantly increased the tensile stiffness of WSPC when compared to the PN reference, up to $63 \%$ and $61 \%$ in warp and weft directions, respectively. The elastic modulus of SP-A reinforced WSPC increased up to $10 \%$ and $12 \%$ when compared to the composites reinforced by P-A structures, in warp and weft directions correspondingly. However, unlike sample SP-45 reinforced WSPC, increasing the SDF gradient changed slightly the tensile stiffness of WSPC. In case P-A reinforced WSPC, increasing the fiber content did not improve the tensile stiffness of warp-wise composites but the tensile strength leveled up to $49 \%$ while the plain reinforcements were embedded in weft direction. The results of this study did not show a substantial increase in the tensile strength of WSPC as compared to the PN reference. Better expressed necking behavior was observed for SP-A reinforced WSPC evidenced by the discrepancies between the values of $\sigma_{\max }$ and $\sigma_{\text {break }}$. As a conclusion, introducing SDF in the plain textile structure with $30^{\circ}$ and $60^{\circ}$ gradients made them the best architectures to improve the tensile properties of WSPC.

\subsection{Matrix/reinforcement bonding state}

The SEM images from surface fracture of tensile failure and further 

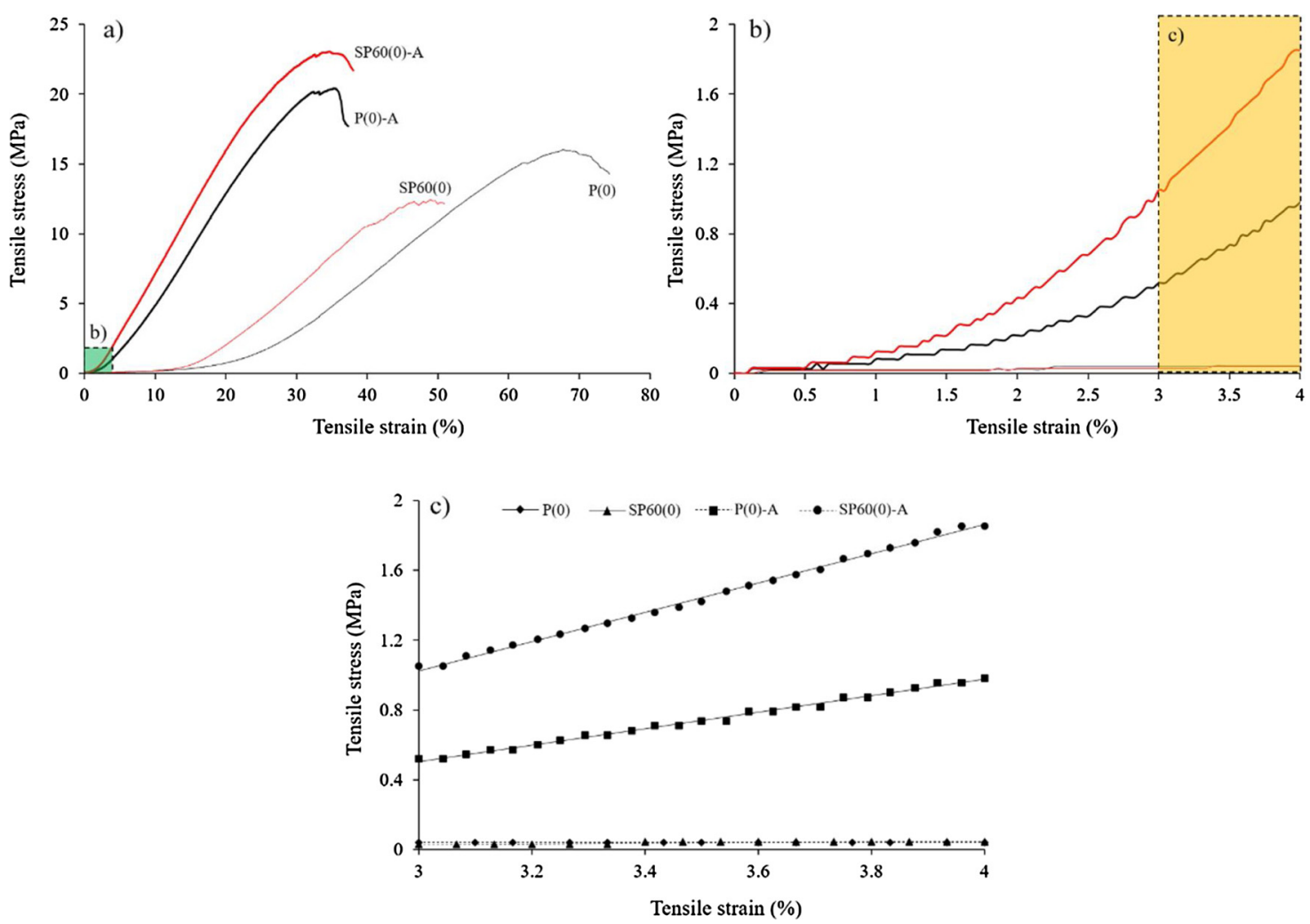

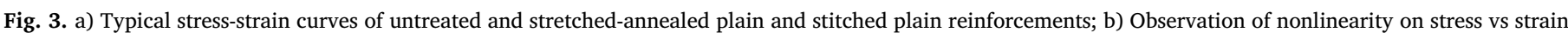

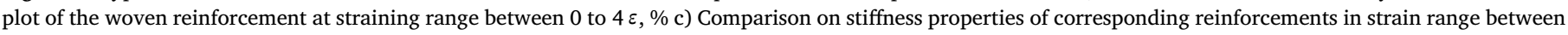
$3-4 \% \varepsilon$.

Table 3

Young's modulus E, maximum tensile strength $\sigma_{\text {break }}$ and strain at break $\varepsilon_{\text {break }}$ obtained from the mechanical tests in tension of treated woven reinforcements.

\begin{tabular}{llll}
\hline Specimens & E (MPa) & $\sigma_{\text {break }}(\mathrm{MPa})$ & $\varepsilon_{\text {break }}(\%)$ \\
\hline Filaments & $9.2 \pm 0.1$ & $3.5 \pm 0.1$ & $45.0 \pm 0.1$ \\
P(0)-A & $21.7 \pm 1.1$ & $19.4 \pm 1.0$ & $28.1 \pm 1.0$ \\
P(90)-A & $3.4 \pm 0.3$ & $19.0 \pm 1.0$ & $46.2 \pm 1.4$ \\
SP30(0)-A & $101.1 \pm 1.7$ & $9.2 \pm 0.5$ & $26.7 \pm 2.1$ \\
SP45(0)-A & $74.8 \pm 1.2$ & $15.9 \pm 0.6$ & $28.6 \pm 1.6$ \\
SP60(0)-A & $85.8 \pm 1.1$ & $23.2 \pm 0.1$ & $17.1 \pm 0.3$ \\
SP30(90)-A & $7.0 \pm 0.8$ & $20.0 \pm 0.8$ & $31.1 \pm 0.5$ \\
SP45(90)-A & $2.2 \pm 0.2$ & $14.1 \pm 0.4$ & $35.7 \pm 1.2$ \\
SP60(90)-A & $3.7 \pm 0.3$ & $22.4 \pm 1.2$ & $37.5 \pm 2.4$ \\
\hline
\end{tabular}

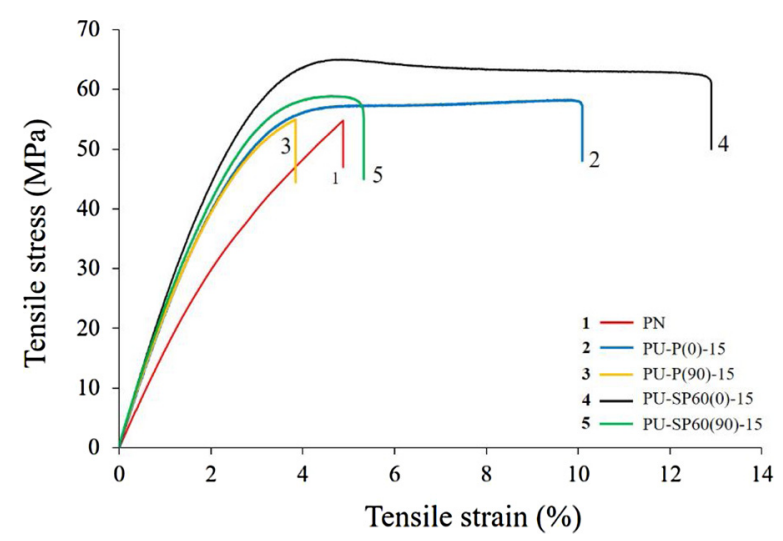

Fig. 4. Stress-strain curves in the tension of P-A and SP-A reinforced WSPC in two principal directions; The neat anionic matrix $\mathrm{PN}$ is presented for reference. For sample, designation see Table 2.
Table 4

Tensile properties of WSPC comprising elastic modulus E, tensile strength $\sigma_{\max }$, tensile stress at break $\left(\sigma_{\text {break }}\right)$ and strain at break $\varepsilon_{\text {break }}$. For sample designation see Table 2.

\begin{tabular}{lllll}
\hline Specimens & $\mathrm{E}(\mathrm{GPa})$ & $\sigma_{\max }(\mathrm{MPa})$ & $\sigma_{\text {break }}(\mathrm{MPa})$ & $\varepsilon_{\text {break }}(\%)$ \\
\hline PN & $1.73 \pm 0.02$ & $56.7 \pm 1.8$ & $56.7 \pm 1.8$ & $5.2 \pm 0.1$ \\
PU-P(0)-15 & $2.51 \pm 0.03$ & $61.7 \pm 1.0$ & $55.7 \pm 1.6$ & $10.7 \pm 0.6$ \\
PU-P(0)-20 & $2.18 \pm 0.04$ & $51.2 \pm 1.9$ & $51.2 \pm 1.9$ & $11.3 \pm 0.6$ \\
PU-P(0)-25 & $2.41 \pm 0.05$ & $54.3 \pm 1.0$ & $54.0 \pm 0.7$ & $11.3 \pm 0.9$ \\
PU-P(90)-15 & $1.71 \pm 0.06$ & $37.9 \pm 0.8$ & $37.9 \pm 0.8$ & $3.9 \pm 0.3$ \\
PU-P(90)-20 & $2.25 \pm 0.05$ & $49.6 \pm 0.8$ & $46.9 \pm 0.7$ & $9.6 \pm 0.8$ \\
PU-P(90)-25 & $2.49 \pm 0.06$ & $56.4 \pm 1.3$ & $55.9 \pm 0.8$ & $7.2 \pm 0.3$ \\
PU-SP30(0)-15 & $2.72 \pm 0.06$ & $64.2 \pm 0.7$ & $60.4 \pm 1.2$ & $9.9 \pm 0.1$ \\
PU-SP45(0)-15 & $2.61 \pm 0.05$ & $60.1 \pm 0.7$ & $61.3 \pm 0.6$ & $8.5 \pm 0.4$ \\
PU-SP60(0)-15 & $2.82 \pm 0.05$ & $64.6 \pm 0.4$ & $59.0 \pm 0.8$ & $12.2 \pm 0.7$ \\
PU-SP30(90)-25 & $2.65 \pm 0.04$ & $62.2 \pm 0.4$ & $57.1 \pm 1.0$ & $5.7 \pm 0.3$ \\
PU-SP45(90)-25 & $2.78 \pm 0.04$ & $59.3 \pm 0.6$ & $58.7 \pm 0.4$ & $4.7 \pm 0.1$ \\
PU-SP60(90)-25 & $2.66 \pm 0.03$ & $58.3 \pm 0.8$ & $57.6 \pm 1.2$ & $5.2 \pm 0.1$ \\
\hline
\end{tabular}

image processing were performed to explain the influence of reinforcement's geometry on matrix/reinforcements interfacial bonding state in WSPC. Fig. 5 shows representative cross-sectional SEM fractographic from tensile failure of PU-P(0)-15, PU-P(90)-25, PU-SP30(0)-15 and PU-SP30(90)-25 samples. The surface fracture configuration evidenced appearance of filament breakage, delamination, and longitudinal splitting. There is no transverse crack detected and the tensile failure formed near crimp regions (interlacing points). The filament longitudinal splitting was merely observed in two principal directions of all WSPC (Fig. 5a-d). The splits only were presented superficially at tensile breakage surface respect to the through-thickness.

Image processing techniques were applied to connect the reinforcement-matrix bonding state at surface fracture with the failure mechanism in WSPC composite. All SEM images were imported to the 

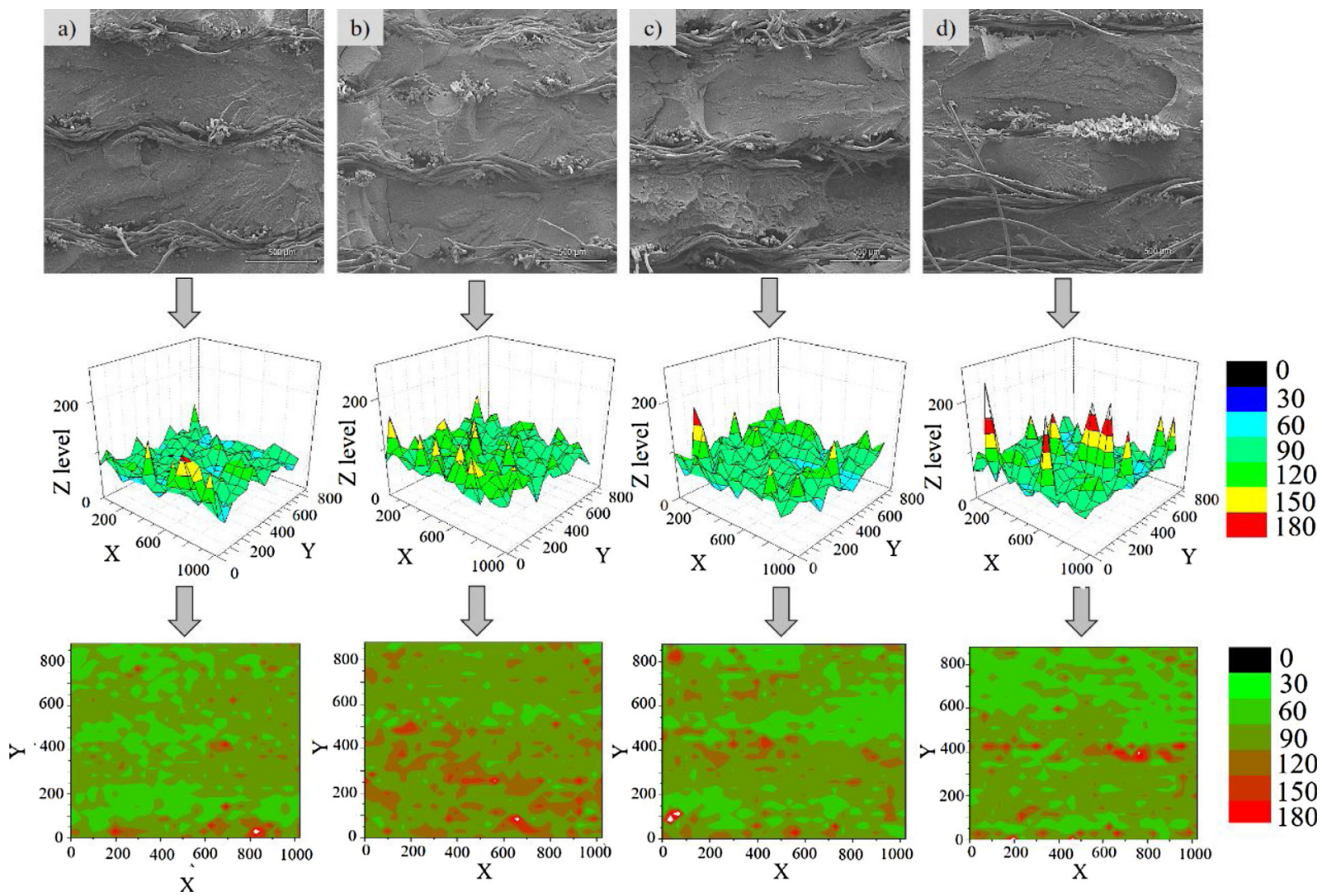

Fig. 5. SEM fractography of tensile fractured surface, surface plot and contour plot (from top to bottom) of a) PU-P(0)-15; b) PU-P(90)-25; c) PU-SP30(0)-15 and d) PU-SP30(90)-25.

MATLAB $^{\circledR}$ software as a greyscale image. The matrix data of images comprising $\mathrm{X}$ and $\mathrm{Y}$ pixels and $\mathrm{Z}$ level were extracted. Image matrices contain numbered columns and rows which were mapped to linearly spaced $\mathrm{X}$ and $\mathrm{Y}$ values respectively. Each cell value in a matrix of SEM image represents a $\mathrm{Z}$ (gray level) that is in the $\mathrm{XY}$ plane by the cell's $\mathrm{X}$ and $\mathrm{Y}$ pixels. Therefore, a higher indentation in a surface plot evidences the composite breakage at alternative levels that signifies gliding the monofilaments out of matrix component at the plane of stress. To have a better observation on surface fractographs evenness of WSPC, the top surface contour plots are presented in Fig. 5a-d.

The matrix/reinforcement interface is crucial parameters to determine the mechanical behavior of composites. During straining the composite material reinforced with textile structures, macro-cracks are formed and propagated through the composites in which the bonding state at the interface is known for transferring the externally applied stresses from the matrix to the reinforcements [27]. As a matter of crack growth resistance, filament bridging and pull-out are major powerful energy dissipation mechanisms in composites materials [28,29]. They are directly correlated to the interfacial bonding between the filaments and the surrounding matrix. Filament breakage occurs while the stored energy at excessive tensile loading approaches to a critical level. The embedded filaments become inactive to tolerate the tensile loads so long as the longitudinal filament's failure exposed within the crack flanks. Otherwise, the filaments are pulled out while the breakage happens along the debonding length. Thus, a shear frictional forces are developed while the fractured filaments slide along the debonded interface which is resulted to endure the tensile stress with filaments and consequently increase the tensile strength of composite material [30]. As a matter fact, observation of uneven surface on micro-fractography cross section of WSPC, evidence the filament failure along the debonded interface.

To reach a logical statement and analyze the surface fracture roughness at the plane of stress, color segmentation of contour plots shown in Fig. 5a-d was required. Image segmentation was applied to divide each contour plot into multiple parts that were targeted to measure the area of $\mathrm{Z}$ value ranges (Fig. 6a-b). Fig. 6a depicts the color segmentation of representative contour plots into $\mathrm{Z}$ levels in ranges of 0-60, 60-90, 90-120 and 120-150 using MATLAB $^{\circledR}$ software. Afterward, an image enhancement technique was utilized to improve the distanced object edges via morphological operations on binary images. As is seen in Fig. $6 \mathrm{~b}$, all measured area of $\mathrm{Z}$ levels in different ranges were plotted due to explain better the mechanical properties of WSPC. All WSPC showed the highest $Z$ value in a range between $60-90$ and lowest in the range between 120-150.

As a conclusion, the indentation of $\mathrm{Z}$ levels of different ranges in SPA reinforced WSPC represented that the plane of stress was strained inconsistently which was resulted from the gliding of intact/bridging monofilaments out of matrix component along larger debonded lengths. Unambiguously, this leads to good matrix/reinforcement interfacial bonding that influence overall permeance of WSPC. The more the strength of interface is, the high steady-state of the crack growth resistance is which restricts debonding but fail in a catastrophic brittle manner.

The schematics of laminated WSPC and composite's cross-section in two principal directions are illustrated in Fig. 7. At the fractured surface of WSPC distribution of stresses arises in an arbitrary direction and can be decomposed into the sum of three principal stresses such as normal $\left(\sigma_{1}\right)$, traverse $\left(\sigma_{2}\right)$ and perpendicular $\left(\sigma_{3}\right)$ stresses (Fig. 7). In an elastic state, the external and internal stresses are identical. Moreover, the tangential stresses take on any value and the element will still be in equilibrium with the applied stresses. After the yield point, this equilibrium becomes distorted. Consequently, the aspect ratio of filaments influences the stress distribution at the straining. As Fig. 7 schematically shows, let us assume composites with higher weft filament's aspect 

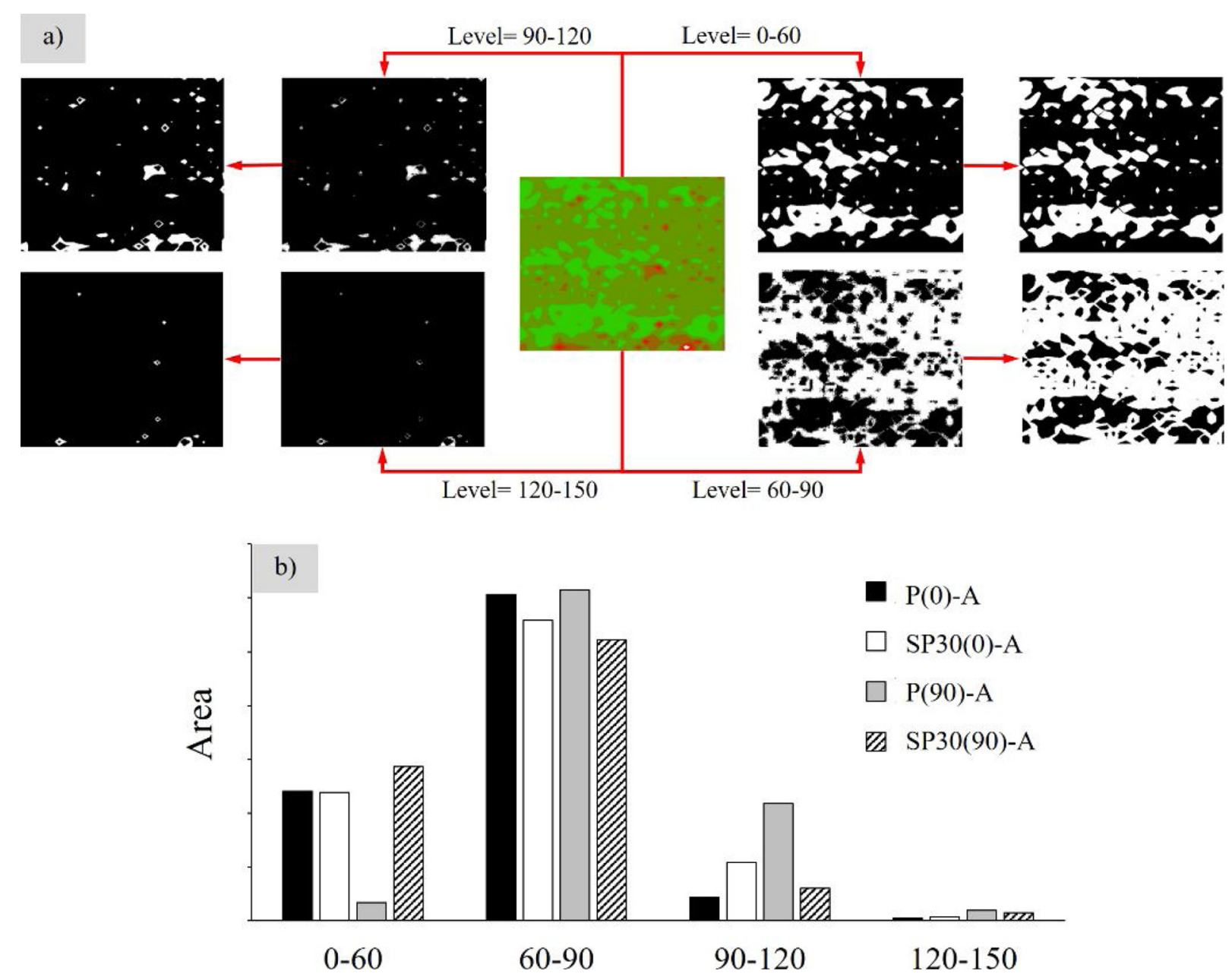

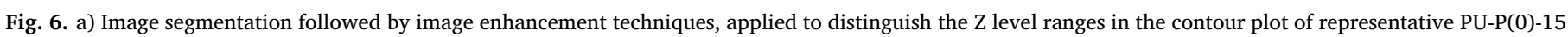
sample; b) Comparing the $\mathrm{Z}$ level ranges of P-A and SP-A reinforced WSPC in two principal directions.

ratio than warps, thus, while the tensile stresses are applied in the warp direction, $\sigma_{2}$ and $\sigma_{3}$ stresses are implied on weft filaments at the plane of stress. Due to the higher aspect ratio in embedded weft filaments, it can be expected the $\sigma_{2}$ and $\sigma_{3}$ stresses are distributed evenly along the fractured surface resulting stiffer composite material in that corresponding direction. Therefore, dimensional analysis of filament's aspect ratio brings logical evidence of stress distribution along sub-elements of the reinforcements.

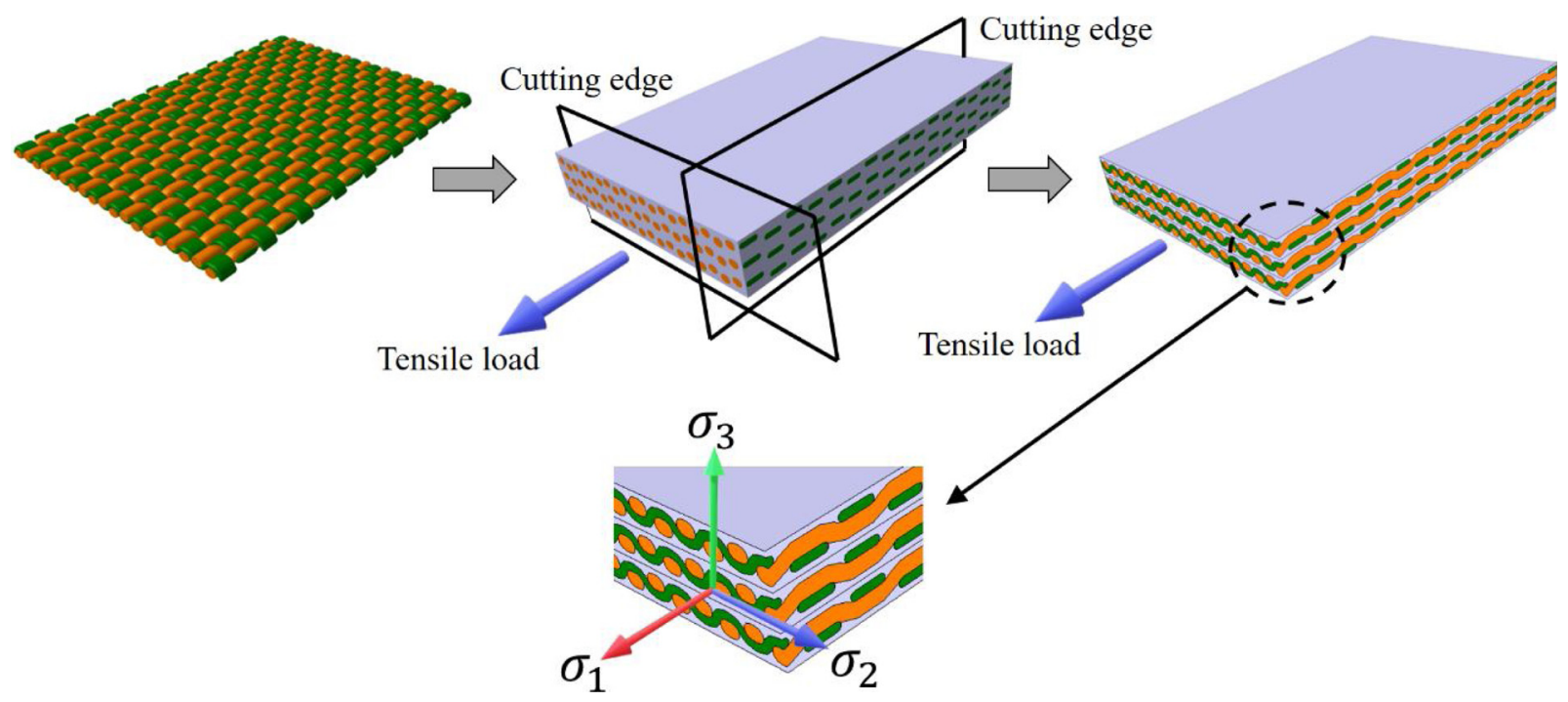

Fig. 7. A representative schematic of WSPC reinforced by the plain textile structure and split in biaxial directions plane surfaces cut. Stress boundary conditions is comprising a projection of implied tensile stresses into the resulting $\sigma_{1}, \sigma_{2}$ and $\sigma_{3}$ stresses. 
a)
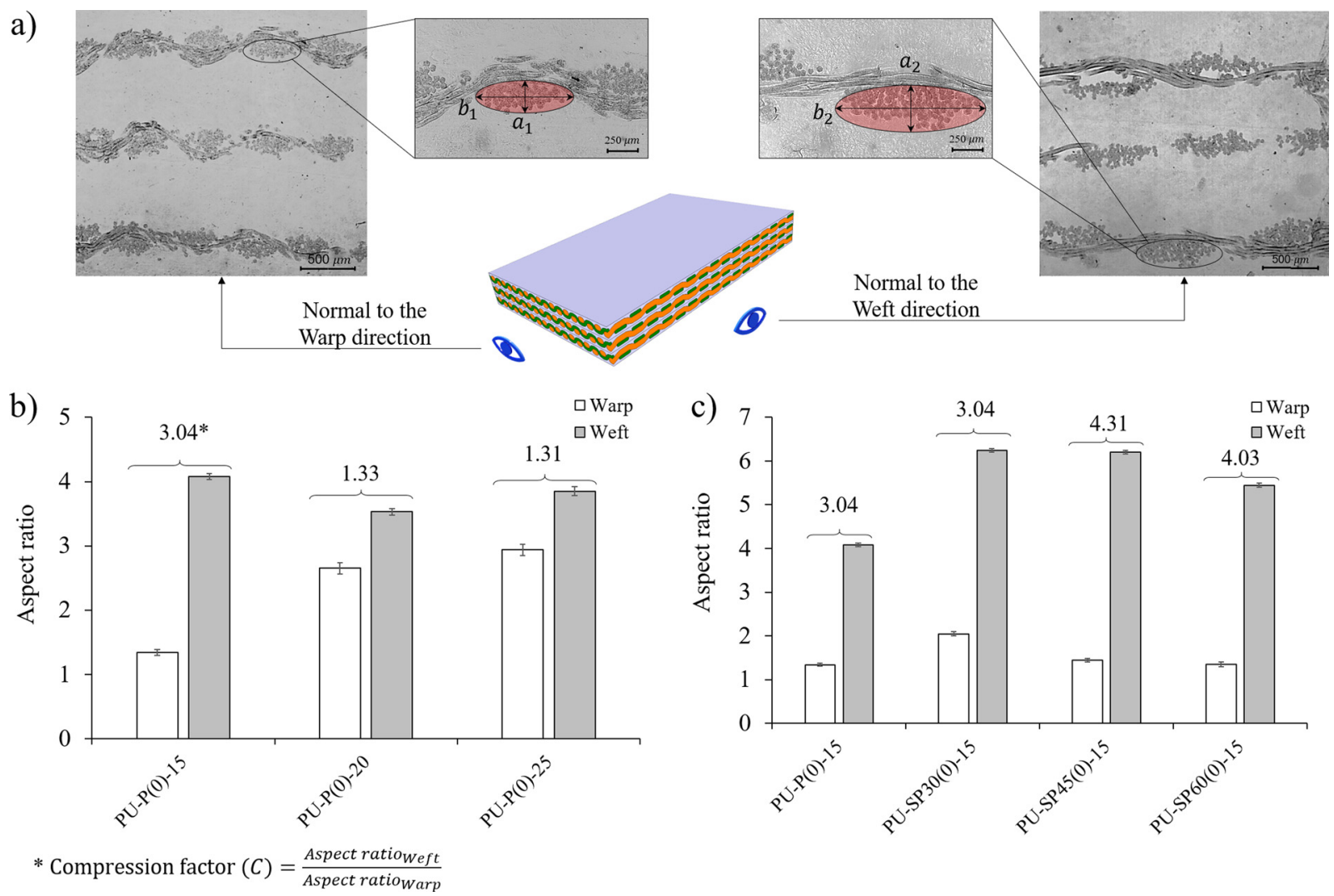

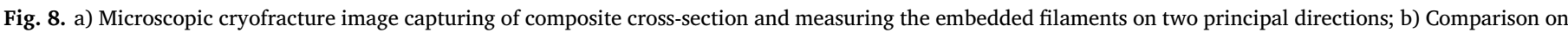

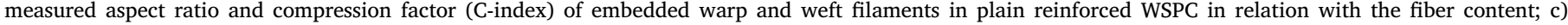
Comparison on filaments aspect ratio and C index in case stitched plain reinforced WSPC in relation with the SDF's gradient.

The image analysis procedure was used to measure the aspect ratio of embedded filaments and provide logical proofs on the above description. In the beginning, superficial microscopic cryofracture images were captured from WSPC cross-section in two principal directions and then image analyzed via OpenCV library. Fig. 8a demonstrates measuring of the major and minor axis of warp and weft monofilament's bundles in which the appendixes 1 and 2 are designated as warp and weft directions respectively. The aspect ratio of filaments in two directions was calculated by $\frac{b_{i}}{a_{i}}, \mathrm{i}=1,2$. Fig. $8 \mathrm{~b}$ shows the calculated aspect ratio of warp and weft filaments in embedded P-A and SP-A woven reinforcements. All embedded filaments depicted higher aspect ratio in the weft direction. The embedded filaments in stitched plain reinforced WSPC had a higher aspect ratio than those reinforced with plain structures.

As it was mentioned above, the compression molding technique was employed to produce WSPC in which the embedded warp and weft filaments are flattened, and their cross-section aspect ratio also is altered. Thus, an index is required to represent in what proportion the filaments become compressed. As it can be seen in Fig. 8b, C index was dedicated for compression factor and calculated by division of weft over the warp aspect ratio in embedded woven reinforcements. The $\mathrm{C}=1$ explains that warp and weft filaments are identically flattered subsequent of compression molding. Comparing the $\mathrm{C}$ value of plain reinforced WSPC with different fiber volume fractions demonstrates that, textile plie incrementation is caused remarkable flattering the warp filaments or increasing their aspect ratio. Although the aspect ratio of weft filaments alters slightly, a significant decrease in the $\mathrm{C}$ value of WSPC can be observed with corresponding to increasing fiber content. Due to this observation, better distribution of principal stresses along the embedded warp filaments and consequently greater tensile properties in weft-wise plain reinforced WSPC with higher fiber content can be explained.
Fig. 8c depicts a comparison on warp and weft filament's aspect ratio in stitched plain reinforced WSPC and the ones reinforced with plain structures as reference sample. As it can be seen in Fig. 8c, in the former case, embedded filaments show a higher filament's aspect ratio and $\mathrm{C}$ values as compared with the later. Therefore, greater tensile properties of stitched plain reinforced WSPC are explained by better stress distribution along the fabric sub-elements when compared with the one reinforced with plain structures. Analogical study on $C$ value of stitched plain reinforced WSPC in relation with the SDF's gradient explain distinct tensile behavior of composite reinforced with SP45-A structures. The embedded SP45-A reinforcements showed higher C value causing disruption on stress distribution during tensile straining.

\section{Conclusions}

Woven reinforced single polymer composites based on polyamide 6 (WSPC) were prepared by a combination of powder-coating of the PA6 reinforcements with PA6 empty microcapsules and compression molding technique (PCCM). The PA6 empty microcapsules were preliminarily synthesized by solution-precipitation AAROP. Conventional plain woven and novel stitched plain reinforcements, patented by Jakob Müller company AG $^{\oplus}$, were used as textile reinforcements in this study. The tensile properties of PA6 based-WSPC were studied in relation to the reinforcement architecture, fiber content, reinforcement orientation. The results showed that embedding of stitched plain reinforcements increased the tensile stiffness by $61-63 \%$ in both warp and weft direction as compared to the PN reference sample. SP-A reinforced WSPC showed increased tensile stiffness values - by ca. $10 \%$ and $12 \%$ compared to the composites reinforced by P-A structures, in warp and weft directions respectively. However, WSPC reinforced with SP45-A showed the lowest tensile properties among SP-A reinforced WSPC.

Image analysis was applied for the stress field analysis of 
cryofracture surface of WSPC. It was hypothesized that the tensile properties of WSPC is associated with the aspect ratio of warp and weft filaments in embedded reinforcements. Therefore, it was evidenced that WSPC reinforced with higher filaments aspect ratio distribute better the principal stresses along the plane of stress. Increasing the fiber volume fraction was caused low compression factor index as well as the high aspect ratio of warp filaments which indirectly explained better tensile properties of WSPC reinforced with higher fiber content. Moreover, due to the high C-index, the distinct tensile behavior of SP45-A reinforced WSPC were explained as compared to those reinforced by SP30-A and SP60-A structures. In the future studies, the finite element model of WSPC reinforced with novel stitched plain structure in the form of a representative volumetric element (RVE) is presented and the validity of the model is confirmed by experimental results.

\section{Declaration of Competing Interest}

The authors declare that they have no known competing financial interests or personal relationships that could have appeared to influence the work reported in this paper.

\section{Acknowledgments}

All authors gratefully acknowledge the support of the project TSSiPRO-NORTE-01-0145-FEDER-000015 funded by the regional operational program NORTE 2020, under the PORTUGAL 2020 Partnership Agreement, through the European Regional Development Fund. The partial support by FEDER funds through the COMPETE program and by national funds through FCT - Foundation for Science and Technology (Portugal) within the project POCI-01-0145-FEDER007136 is also acknowledged. SDT acknowledges FCT for the financial support through the project SFRH/BD/94759/2013. Moreover, the first author thanks for the financial support of the European Regional Development Fund ERDF, through the operational program for COMPETE 2020 and by FCT within the project PTDC/EMEEME/30967/ 2017 and NORTE-0145-FEDER-030967. Additionally, N. Dencheva is also grateful for the financial support of FCT in the frames of the strategic project UID/CTM/50025/2013 and the personal programcontract CTTI-51/18-IPC.

Data availability statement

The raw/processed data required to reproduce these findings cannot be shared at this time due to legal or ethical reasons.

\section{Appendix A. Supplementary data}

Supplementary material related to this article can be found, in the online version, at doi:https://doi.org/10.1016/j.mtcomm.2020. 101068.

\section{References}

[1] K.P. Matabola, A.R. Vries, F.S. Moolman, A.S. Luyt, Single polymer composites: a review, J. Mater. Sci. 44 (2009) 6213-6222.

[2] D. Yao, R. Li, P. Nagarajan, Single-polymer composites based on slowly crystallizing polymers, Polym. Eng. Sci. 46 (2006) 1223-1230.

[3] F.P. La Mantia, D. Curto, R. Scaffaro, Recycling of dry and wet polyamide 6, J. Appl. Polym. Sci. 86 (2002) 1899-1903.
[4] F.V. Lacroix, M. Werwer, K. Schulte, Solution impregnation of polyethylene fibre/ polyethylene matrix composites, Compos. Part A Appl. Sci. Manuf. 29 (1998) 371-376.

[5] P.J. Hine, A. Astruc, I.M. Ward, Hot compaction of polyethylene naphthalate, J. Appl. Polym. Sci. 93 (2004) 796-802.

[6] I.M. Ward, P.J. Hine, The science and technology of hot compaction, Polymer (Guildf). 45 (2004) 1413-1427.

[7] Y. Gong, G. Yang, Single polymer composites by partially melting recycled polyamide 6 fibers: preparation and characterization, J. Appl. Polym. Sci. 118 (2010) 3357-3363.

[8] B. Alcock, N.O. Cabrera, N.-M. Barkoula, Z. Wang, T. Peijs, The effect of temperature and strain rate on the impact performance of recyclable all-polypropylene composites, Compos. Part B Eng. 39 (2008) 537-547.

[9] P. Dubois, O. Coulembier, J.-M. Raquez, Handbook of Ring-Opening Polymerization, John Wiley \& Sons, Weinheim, 2009.

[10] Y. Gong, A. Liu, G. Yang, Polyamide single polymer composites prepared via in situ anionic polymerization of $\varepsilon$-caprolactam, Compos. Part A Appl. Sci. Manuf. 41 (2010) 1006-1011.

[11] N. Dencheva, Z. Denchev, A.S. Pouzada, A.S. Sampaio, A.M. Rocha, Structure-properties relationship in single polymer composites based on polyamide 6 prepared by in-mold anionic polymerization, J. Mater. Sci. 48 (2013) 7260-7273.

[12] N. Dencheva, A.S. Sampaio, F.M. Oliveira, A.S. Pouzada, A.M. Brito, Z. Denchev, Preparation and properties of polyamide-6-based thermoplastic laminate composites by a novel in-mold polymerization technique, J. Appl. Polym. Sci. 131 (2014) 40083-40094.

[13] F. Oliveira, N. Dencheva, P. Martins, S. Lanceros-Méndez, Z. Denchev, A new approach for preparation of metal-containing polyamide/carbon textile laminate composites with tunable electrical conductivity, J. Mater. Sci. 53 (2018) 11444-11459.

[14] S.D. Tohidi, A.M. Rocha, N.V. Dencheva, Z. Denchev, Single polymer laminate composites by compression molding of knitted textiles and microparticles of polyamide 6: preparation and structure-properties relationship, Compos. Part A Appl. Sci. Manuf. 109 (2018) 171-183.

[15] Y. Gong, G. Yang, Manufacturing and physical properties of all-polyamide composites, J. Mater. Sci. 44 (2009) 4639-4644.

[16] C.Z.P. Júnior, L.H. De Carvalho, V.M. Fonseca, S.N. Monteiro, J.R.M. d'Almeida, Analysis of the tensile strength of polyester/hybrid ramie-cotton fabric composites, Polym. Test. 23 (2004) 131-135.

[17] T. Osada, A. Nakai, H. Hamada, Initial fracture behavior of satin woven fabric composites, Compos. Struct. 61 (2003) 333-339.

[18] O. Asi, Effect of different woven linear densities on the bearing strength behaviour of glass fiber reinforced epoxy composites pinned joints, Compos. Struct. 90 (2009) 43-52.

[19] S.V. Lomov, D.S. Ivanov, T.C. Truong, I. Verpoest, F. Baudry, K.V. Bosche, H. Xie, Experimental methodology of study of damage initiation and development in textile composites in uniaxial tensile test, Compos. Sci. Technol. 68 (2008) 2340-2349.

[20] F. Gao, L. Boniface, S.L. Ogin, P.A. Smith, R.P. Greaves, Damage accumulation in woven-fabric CFRP laminates under tensile loading: part 1. Observations of damage accumulation, Compos. Sci. Technol. 59 (1999) 123-136.

[21] M. Todo, K. Takahashi, P. Béguelin, H.H. Kausch, Strain-rate dependence of the tensile fracture behaviour of woven-cloth reinforced polyamide composites, Compos. Sci. Technol. 60 (2000) 763-771.

[22] C. Brêda, N. Dencheva, S. Lanceros-Méndez, Z. Denchev, Preparation and properties of metal-containing polyamide hybrid composites via reactive microencapsulation, J. Mater. Sci. 51 (2016) 10534-10554.

[23] N. Dencheva, Z. Denchev, S. Lanceros-Méndez, T. Ezquerra Sanz, One-Step In Situ Synthesis of Polyamide Microcapsules With Inorganic Payload and Their Transformation into Responsive Thermoplastic Composite Materials, Macromol. Mater. Eng. 301 (2016) 119-124.

[24] A.B. Strong, Fundamentals of Composites Manufacturing: Materials, Methods and Applications, Society of Manufacturing Engineers, Michigan, 2008.

[25] J. Hu, Structure and Mechanics of Woven Fabrics, Elsevier, Cambridge, 2004.

[26] T. Ishikawa, T.-W. Chou, One-dimensional micromechanical analysis of woven fabric composites, AIAA J. 21 (1983) 1714-1721.

[27] K.G. Dassios, C. Galiotis, V. Kostopoulos, M. Steen, Direct in situ measurements of bridging stresses in CFCCs, Acta Mater. 51 (2003) 5359-5373.

[28] C.-H. Hsueh, Interfacial debonding and fiber pull-out stresses of fiber-reinforced composites, Mater. Sci. Eng. A. 123 (1990) 1-11.

[29] K.G. Dassios, A review of the pull-out mechanism in the fracture of brittle-matrix fibre-reinforced composites, Adv. Compos. Lett. 16 (2007) 096369350701600102.

[30] J.K. Wells, P.W.R. Beaumont, Debonding and pull-out processes in fibrous composites, J. Mater. Sci. 20 (1985) 1275-1284. 